\title{
Kinship Analysis with Diallelic SNPs - Experiences with the SNPforlD Multiplex in an ISO17025 Accreditated Laboratory
}

\author{
Claus Børsting Martin Mikkelsen Niels Morling
}

Section of Forensic Genetics, Department of Forensic Medicine, Faculty of Health Sciences, University of Copenhagen, Denmark

\section{Keywords}

SNP · SNPforlD · Forensic genetics .

Relationship testing - DNA mixtures

\section{Summary}

Background: The mutation rate of single nucleotide polymorphisms (SNPs) is estimated to be 100,000 times lower than that of short tandem repeats (STRs), which makes SNPs very suitable for relationship testing. The SNPforlD multiplex assay was the first SNP typing assay that was a real alternative to the commonly used STR kits in kinship and crime case work and the first SNP assay to be validated in a forensic laboratory accredited according to the ISO17025 standard. Methods: A total of 54 crime case samples were typed with the SNPforlD multiplex assay. 30 samples from relationship cases were sequenced in selected SNP loci. Results: It was demonstrated that mixtures were easily detected with the SNPforlD assay by analyzing the signal strengths of the detected alleles. Unusual imbalances in signal strengths that were observed in a few individuals could be explained by unexpected SNPs in one of the primer binding sites. A complicated relationship case with four closely related individuals is presented. Conclusion: Mixtures can be detected with bi-allelic SNPs. The SNPforlD assay is a very useful supplement to the STR kits in relationship testing.

\author{
Schlüsselwörter \\ SNP . SNPforlD · Forensische Genetik · \\ Abstammungsbegutachtung · DNA-Mischungen
}

\section{Zusammenfassung}

Hintergrund: Die Mutationsrate von Single-NucleotidePolymorphismen (SNPs) ist $100000 \mathrm{Mal}$ niedriger als die Mutationsrate von Short-Tandem-Repeats (STRs). Die kleine Mutationsrate macht SNPs sehr nützlich für die Abstammungsbegutachtung. Der SNPforlD-Multiplex war der erste SNP-Typisierungstest, der eine gute Ergänzung und vielleicht ein echte Alternative zu STR-Kits in der Abstammungsbegutachtung war, und der erste forensische SNP-Test, der nach dem ISO17025-Standard akkreditiert worden ist. Methoden: Insgesamt 54 Proben von Kriminalfällen wurden mit dem SNPforID-MultiplexTest untersucht. Weiterhin wurden 30 Proben von Abstammungsfällen in ausgewählten SNP-Loci sequenziert. Ergebnisse: Es wurde gezeigt, dass DNA-Mischungen leicht mit dem SNPforlD-Test durch die Analyse der Signalstärke der detektierten Allele erkannt werden konnten. Ungewöhnliche Ungleichgewichte in SNP-Signalstärken in einigen Proben konnten durch zusätzliche/unerwartete SNPs in einer der Primer-Bindungsstellen erklärt werden. Ein komplizierter Abstammungsfall mit vier eng verwandten Individuen wird als Beispiel vorgestellt. Schlussfolgerung: DNA-Mischungen können mit bi-allelischen SNPs erkannt werden. Der SNPforlD-Test ist eine sehr nützliche/wertvolle Ergänzung zu STR-Kits in der Abstammungsbegutachtung.

\section{KARGER \\ Fax +497614520714 \\ Information@Karger.de}

www.karger.com
(C) 2012 S. Karger GmbH, Freiburg

$1660-3796 / 12 / 0393-0195 \$ 38.00 / 0$

Accessible online at:

www.karger.com/tmh 


\section{Introduction}

The number of single nucleotide polymorphisms (SNPs) in the human genome is estimated to be 10-11 million with an average of 1 SNP per 275 base pairs (bp). The vast majority of SNPs have only two alleles, and the average mutation rate at a particular base pair position is extremely low (approximately $10^{-7}$ to $10^{-9}$ ). For these reasons, SNPs have been used extensively to map the history of populations and for studying the association between SNP markers and traits and diseases. Within the forensic community, SNPs have attracted a lot of attention in the last decade, and this is likely to continue as forensic genetic research now includes markers that reveal information about ethnic origin, physical traits, molecular pathology, etc. For human identification and relationship testing, SNPs have already proved to be valuable markers and SNPs are used by some laboratories in routine case work investigations. SNPs are mainly used as supplementary markers, but there are situations where SNPs may be the best choice of markers. If the DNA is highly degraded, there is a much higher chance of obtaining results with SNP markers than with short tandem repeat (STR) markers, because SNPs may be amplified on very short amplicons ( $<100$ bp) [1-5]. Furthermore, the commonly used STR kits amplify 15-17 STRs, and one mutation is expected to occur in one of the loci typed with these kits in approximately $3 \%$ of all meioses. If $1-2$ genetic inconsistencies are detected between a child and the alleged parents in a relationship case, it can be difficult to draw a conclusion because the inconsistencies may be mutations or indicate that one of the alleged parents may not be the true biological parent [6.-10]. In contrast, mutations occur 100,000 times less frequently in SNPs than in STRs, and inconsistencies caused by mutations in SNP loci are extremely rare.

The SNPforID consortium (www.snpforid.org) developed a SNP typing assay for human identification purposes that made it possible to amplify 52 SNPs from diminutive amounts of genomic DNA [1]. All SNP loci were amplified in one PCR reaction, and the SNPs were analyzed by two single base extension (SBE) reactions and capillary electrophoresis. The SBE products were injected into the same capillary with 5 -min intervals and analyzed in one data file $[1,11]$.

The main criteria for selection of the SNP loci in the SNPforID multiplex were i) that the SNPs were highly polymorphic in most human populations (heterozygosity $>0.32$ ), ii) that the SNPs were not in linkage disequilibrium, iii) that the SNPs were unlikely to be associated with cellular functions or with STR loci commonly used in forensic genetics investigations, and iv) that all SNPs could be amplified by PCR in one reaction [1].

The sensitivity and the overall robustness of the SNPforID multiplex assay were improved when the assay was validated for forensic genetic case work according to the ISO 17025 standard. In the validation process, the number of SNPs typed
Fig. 1. Case example. a Hypothesis $\mathrm{H}_{1}$ : The father of the mother is the father of the child. b Hypothesis $\mathrm{H}_{2}$ : The brother of the mother is the father of the child. c STR and SNP typing results at the three loci where mismatches were detected between $\mathrm{C}$ and AF2.

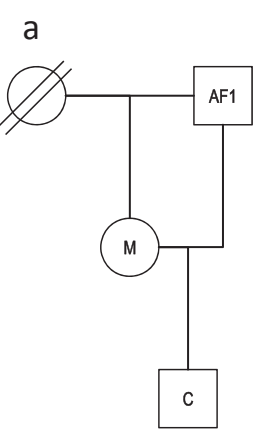

b

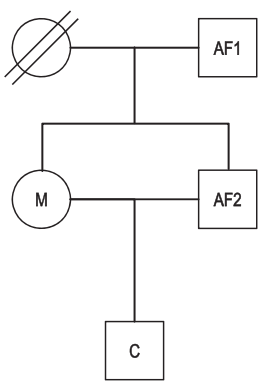

C

\begin{tabular}{lrrrr}
\hline & M & C & AF1 & AF2 \\
\hline D13S317 & 12 & $8 ; 12$ & $8 ; 12$ & 12 \\
rs1029047 & T & A;T & A & T \\
rs733164 & A;G & G & A;G & A \\
\hline
\end{tabular}

with the assay was reduced from 52 to 49 to allow optimization of the SBE primer design and simplification of the analysis of the electropherograms [11]. With the improved assay, full SNP profiles were obtained from only $100 \mathrm{pg}$ of genomic DNA [12]. The lengths of the PCR amplicons in the SNPforID multiplex ranged from 65 to $115 \mathrm{bp}$. Full SNP profiles were generated from highly degraded DNA samples, where it was not possible to amplify any or just a few STR loci with the commercial STR kits [1, 3, 5]. Typing data from populations on all six continents confirmed that the SNPs are polymorphic in all populations, and there was no evidence of linkage disequilibrium between any of the selected SNPs. The mean match probability ranged from $10^{-14}$ to $10^{-21}$, and the paternity indices ranged from $10^{5}$ to $10^{6}$ for trios $[1,11,13-17]$. More than 75 population groups have been typed for these SNPs since the assay was developed, and the allele frequencies are freely available at the SNPforID homepage [18].

Here, we address the issues of mixture identification with bi-allelic SNP markers and identification of silent SNP alleles, and we present an illustrative case example of how useful the SNPforID multiplex may be in complicated relationship cases.

\section{Material and Methods}

\section{Sample Materials and DNA Preparations}

50 trace samples and 4 reference samples from crime cases were selected. The 50 trace samples consisted of 30 single source samples and 20 twoperson mixtures. The four reference samples were from the same case (fig. 1). In addition, 30 samples from paternity and immigration case work were selected for sequencing of individual SNP loci.

Reference samples and samples from paternity and immigration case work were collected as buccal swabs on FTA ${ }^{\circledR}$ cards (Whatman, Maidstone, UK) or as whole blood. PCR was performed on washed and dried $1.2 \mathrm{~mm}$ FTA card punches as previously described $[11,19]$. DNA was isolated from whole blood using the EZ-1 DNA Investigator kit (Qiagen, Hilden, Germany) and an EZ1 Advanced XL (Qiagen) according to the manufacturer's instructions. DNA was isolated from the trace samples using Chelex-100 resin [19]. The work was approved by the Danish ethical committee (H-1-2011-081). 
Table 1. Silent and partially silent alleles identified by sequencing

\begin{tabular}{|c|c|c|c|c|}
\hline Locus & $\begin{array}{l}\text { Observation with } \\
\text { SNPforID assay } \dagger\end{array}$ & $\begin{array}{l}\text { Origin of } \\
\text { samples }\end{array}$ & Primers for sequencing & $\begin{array}{l}\text { Detected variation in SNPforID } \\
\text { primer }\end{array}$ \\
\hline rs938283 & partially silent allele $(\mathrm{T})$ & $\begin{array}{l}\text { Somalia } \\
\text { Congo }\end{array}$ & $\begin{array}{l}\text { forward-GGACTGAATCATGCCСТCTC } \\
\text { reverse-GAAGGCTTCTCTTTGGCTTG }\end{array}$ & $\begin{array}{l}\mathrm{G} \rightarrow \mathrm{T} \text { in position }-9 \text { of the reverse } \\
\mathrm{PCR} \text { primer }\end{array}$ \\
\hline rs2830795 & silent allele (A) & Congo & $\begin{array}{l}\text { forward-ATAGGAAGGCTGCAGGTTGA } \\
\text { reverse-GGGGAGGTTGTCATCAGAGA }\end{array}$ & $\mathrm{A} \rightarrow \mathrm{T}$ in position -2 of the $\mathrm{SBE}$ primer \\
\hline rs1031825 & silent allele & Congo & $\begin{array}{l}\text { forward-CCTGCATCTTCTTCCAGGAG } \\
\text { reverse-TTAAGTGCCAAGCCCTATGC }\end{array}$ & apparent deletion of locus ${ }^{\ddagger}$ \\
\hline rs763869 & partially silent allele $(\mathrm{C})$ & Denmark & $\begin{array}{l}\text { forward-TAGGGACACAGCCAAACCAT } \\
\text { reverse-TTGAACAACACAACGACAAATG }\end{array}$ & $\mathrm{C} \rightarrow \mathrm{A}$ in position -9 of the $\mathrm{SBE}$ primer \\
\hline rs1029047 & partially silent allele $(\mathrm{A})$ & $\begin{array}{l}\text { Somalia } \\
\text { Congo }\end{array}$ & $\begin{array}{l}\text { forward-GGAAATTTGTAGATCATTCTGGGTA } \\
\text { reverse-CACTGAAGTTTCAGGGCTCA }\end{array}$ & $\mathrm{A} \rightarrow \mathrm{T}$ in position -9 of the $\mathrm{SBE}$ primer \\
\hline
\end{tabular}

\section{STR Analyses}

The four reference samples in the case example were typed for 18 autosomal STRs (CSF1PO, D13S317, D16S539, D18S51, D19S433, D21S11, D2S1338, D3S1358, D5S818, D7S820, D8S1179, FGA, TH01, TPOX, vWA, F13A01, F13B, FESFPS) using the AmpFlSTR ${ }^{\circledR}$ Identifiler $^{\circledR}$ PCR Amplification Kit (Applied Biosystems, Carlsbad, CA, USA) and the GenePrint ${ }^{\circledR}$ FFFL fluorescent STR kit (Promega, Madison, WI, USA). For the AmpFlSTR Identifiler Kit, one $1.2 \mathrm{~mm}$ FTA card punch was mixed with $4 \mu \mathrm{l}$ AmpFlSTR ${ }^{\circledR}$ PCR reaction mix (Applied Biosystems), $2 \mu \mathrm{l}$ AmpFlSTR Identifiler primer set (Applied Biosystems), $0.2 \mu \mathrm{l}$ AmpliTaq Gold $^{\circledR}$ (Applied Biosystems), and $4 \mu \mathrm{lddH_{2 }}$ O. The following cycle program was used: denaturation and enzyme activation at $95^{\circ} \mathrm{C}$ for $11 \mathrm{~min}$, 24 cycles of $94^{\circ} \mathrm{C}$ for $1 \mathrm{~min}, 59^{\circ} \mathrm{C}$ for $1 \mathrm{~min}$ and $72^{\circ} \mathrm{C}$ for $1 \mathrm{~min}$, followed by $60 \mathrm{~min}$ at $60^{\circ} \mathrm{C}$. For the GenePrint FFFL kit, one $1.2 \mathrm{~mm}$ FTA card punch was mixed with $1 \mu$ l GoldST*R 10x buffer (Promega), $1 \mu \mathrm{l} 10 \mathrm{x}$ primer mix (Promega), $0.08 \mu \mathrm{l}$ AmpliTaq Gold (Applied Biosystems) and $8 \mu \mathrm{lddH_{2 }}$ O. The following cycle program was used: denaturation and enzyme activation at $95^{\circ} \mathrm{C}$ for $11 \mathrm{~min}, 10$ cycles of $94^{\circ} \mathrm{C}$ for $1 \mathrm{~min}, 60^{\circ} \mathrm{C}$ for 1 minand $70{ }^{\circ} \mathrm{C}$ for $1.5 \mathrm{~min}$, followed by 14 cycles of $90{ }^{\circ} \mathrm{C}$ for $1 \mathrm{~min}, 60^{\circ} \mathrm{C}$ for $1 \mathrm{~min}$ and $70{ }^{\circ} \mathrm{C}$ for $1.5 \mathrm{~min}$, followed by $60 \mathrm{~min}$ at $60{ }^{\circ} \mathrm{C}$. PCR reactions were performed in a GeneAmp ${ }^{\circledR}$ PCR system 9700 thermal cycler (Applied Biosystems). A total of $1.5 \mu \mathrm{l}$ PCR product was mixed with $15 \mu \mathrm{l} \mathrm{Hi}-\mathrm{Di}^{\mathrm{TM}}$ formamide (Applied Biosystems) and $0.3 \mu \mathrm{l} \mathrm{GeneScan}{ }^{\mathrm{TM}}$ $500 \mathrm{HD} \mathrm{Liz}^{\circledR}$ size standard (Applied Biosystems) or $0.1 \mu \mathrm{l} \mathrm{GeneScan}{ }^{\mathrm{TM}}$ $400 \mathrm{HD} \mathrm{ROX}^{\mathrm{TM}}$ size standard (Applied Biosystems), and analyzed on a 3130xl Genetic Analyzer (Applied Biosystems) with a $36 \mathrm{~cm}$ capillary array, POP-4 ${ }^{\mathrm{TM}}$ polymer (Applied Biosystems) and 6 second injections at $3,000 \mathrm{~V}$. Data were analyzed independently by two analysts using GeneScan $^{\circledR}$ analysis software v. 3.7 and Genotyper ${ }^{\circledR}$ analysis software v. 3.7 (Applied Biosystems), and the results were compared. The minimum peak height was set to 50 relative fluorescence units (RFUs) for all dyes. All samples were analyzed at least twice, and the results from the two experiments were compared. If the results differed, the sample was analyzed a third time.

\section{SNP Analyses}

A total of 49 autosomal SNPs were amplified by PCR in $25 \mu \mathrm{l}$ reactions containing one $1.2 \mathrm{~mm}$ FTA card punch or $1 \mu \mathrm{l}$ DNA solution, 1x GeneAmp ${ }^{\circledR}$ PCR buffer I (Applied Biosystems), 8 mmol/1 $\mathrm{MgCl}_{2}$ (Applied Biosystems), $700 \mu \mathrm{mol} / \mathrm{l}$ of each dNTP (GE Healthcare, Munich, Germany), 0.01-0.17 $\mu \mathrm{M}$ of each primer (DNA Technology, Risskov, Denmark), and 2 U AmpliTaq Gold DNA polymerase (Applied Biosystems) [11]. The following cycle program was used: denaturation at $94{ }^{\circ} \mathrm{C}$ for $5 \mathrm{~min}$ followed by 35 cycles of $95^{\circ} \mathrm{C}$ for $30 \mathrm{~s}, 60^{\circ} \mathrm{C}$ for $30 \mathrm{~s}$ and $65^{\circ} \mathrm{C}$ for $30 \mathrm{~s}$ fol- lowed by $7 \mathrm{~min}$ at $65^{\circ} \mathrm{C}$. PCRs were performed in a GeneAmp PCR system 9700 thermal cycler (Applied Biosystems). Excess of PCR primers and dNTPs were removed by addition of a freshly prepared mix of $0.75 \mu \mathrm{l}$ (1 U/ $\mathrm{Ul}$ ) shrimp alkaline phosphatase (Amersham Pharmacia Biotech, Piscataway, NJ, USA) and 0.023 $\mu \mathrm{l}(10 \mathrm{U} / \mu \mathrm{l})$ Exonuclease I (Amersham Pharmacia Biotech) to $2.5 \mu \mathrm{l} \mathrm{PCR}$ product and incubation at $37^{\circ} \mathrm{C}$ for $1 \mathrm{~h}$ followed by incubation at $75^{\circ} \mathrm{C}$ for $15 \mathrm{~min}$.

SBE reactions were performed in $8 \mu \mathrm{l}$ reaction volumes containing $1 \mu \mathrm{l}$ purified PCR product, $4 \mu \mathrm{l} \mathrm{SNaPshot}{ }^{\circledR}$ reaction mix (Applied Biosystems), $1 \mu \mathrm{l} \mathrm{SBE}$ primer mix (DNA Technology) and $2 \mu \mathrm{lddH_{2 }} \mathrm{O}$. The SBE primer mix was diluted in $160 \mathrm{mmol} / 1$ ammonium sulphate (SigmaAldrich, St. Louis, MO, USA) to minimize primer-dimer artifacts. The SBE reaction was performed in GeneAmp PCR system 9700 thermal cyclers (Applied Biosystems) with 30 cycles of $96{ }^{\circ} \mathrm{C}$ for $10 \mathrm{~s}, 50^{\circ} \mathrm{C}$ for $5 \mathrm{~s}$, and $60{ }^{\circ} \mathrm{C}$ for $30 \mathrm{~s}$. Excess nucleotides were removed by addition of $1 \mu \mathrm{l}$ (1 U/ $/$ l) shrimp alkaline phosphatase to the SBE mix and incubation at $37{ }^{\circ} \mathrm{C}$ for $30 \mathrm{~min}$ followed by $75{ }^{\circ} \mathrm{C}$ for $15 \mathrm{~min}$. $2 \mu \mathrm{l} \mathrm{SBE}$ products were mixed with $20 \mu \mathrm{l} \mathrm{Hi-Di}$ formamide (Applied Biosystems) and $0.1 \mu \mathrm{Ge}$ neScan ${ }^{\mathrm{TM}} 120 \mathrm{Liz}^{\circledR}$ size standard (Applied Biosystems). The SBE products were analyzed by capillary electrophoresis using 3130xl Genetic Analyzers (Applied Biosystems) with $36 \mathrm{~cm}$ capillary arrays and POP-4 polymer (Applied Biosystems) as previously described [1, 11]. Analysis was made using GeneScan Analysis 3.7 with peak thresholds set to 50 RFUs. Allele calls were made independently by two analysts using Genotyper 3.7 macros, where peaks detected in pre-defined allele windows with peak heights larger than 10\% (blue color), $7 \%$ (green color) or 5\% (yellow and red color) of the maximum peak height in the respective color were labeled with allele name, peak height, and size. Every phenotype call was evaluated based on the peak height(s) of the allele(s) according to predefined guidelines for allele calling [11]. The two independent analyses were compared. If the allele calls differed, the analyses of the electropherograms were repeated by both analysts. If the results differed after the second analysis, the results were failed, and the sample was investigated again. All samples were analyzed at least twice, and the results from the two experiments were compared. If the results differed, the sample was analyzed a third time.

\section{DNA Sequencing}

PCR primers were designed for 5 SNP loci (table 1) using Primer3 (http:// frodo.wi.mit.edu/primer3/). One $1.2 \mathrm{~mm}$ FTA card punch or $1 \mu \mathrm{l}$ DNA solution was mixed with $1 \mathrm{x}$ GeneAmp ${ }^{\circledR}$ PCR buffer I (Applied Biosystems), 2.5 or $3.5 \mathrm{mmol} / 1 \mathrm{MgCl}_{2}$ (Applied Biosystems), $400 \mu \mathrm{mol} / \mathrm{l}$ of each dNTP (GE Healthcare), $0.2 \mu \mathrm{mol} / \mathrm{l}$ of each primer (DNA Technology), and $2 \mathrm{U}$ AmpliTaq Gold DNA polymerase (Applied Biosystems). The following cycle 
Fig. 2. Normalized peak height ratios from a 30 single source samples $\mathbf{b}$ and 20 two-person mixtures typed with the SNPforID multiplex assay.
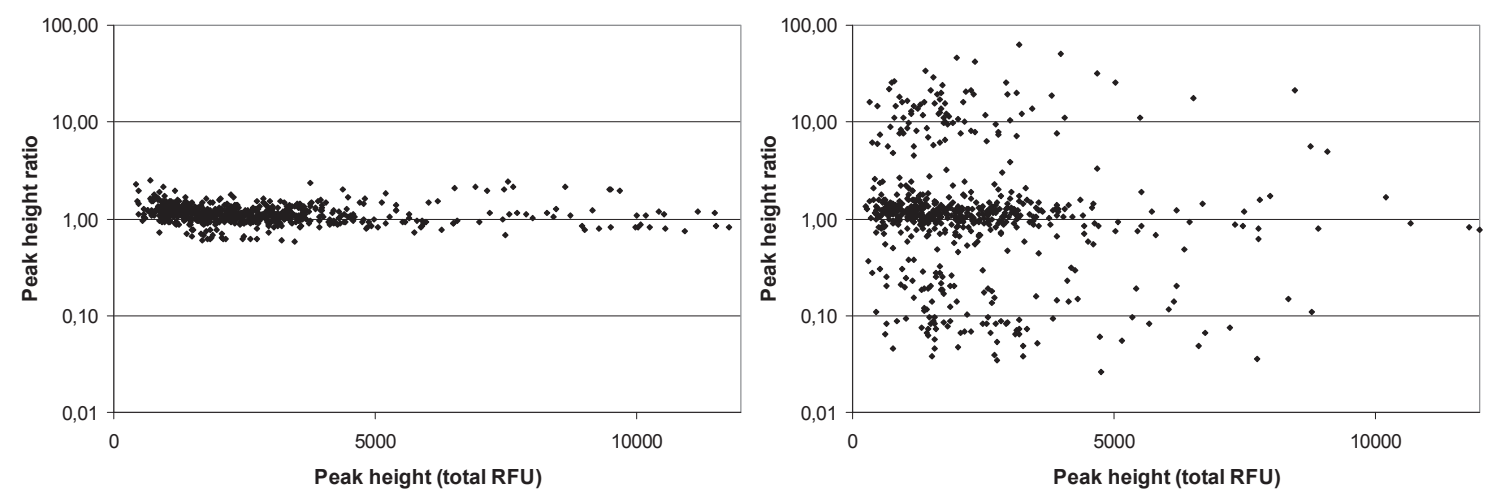

program was used: denaturation at $95^{\circ} \mathrm{C}$ for $5 \mathrm{~min}$ followed by 30 cycles of $95{ }^{\circ} \mathrm{C}$ for $15 \mathrm{~s}, 60^{\circ} \mathrm{C}$ or $58^{\circ} \mathrm{C}$ for $15 \mathrm{~s}$ and $72{ }^{\circ} \mathrm{C}$ for $30 \mathrm{~s}$ followed by $5 \mathrm{~min}$ at $72{ }^{\circ} \mathrm{C}$. PCR products were sequenced using the BigDye Terminator Kit (Applied Biosystems) as recommended by the manufacturer. The results were analyzed on a 3130xl Genetic Analyzer (Applied Biosystems) with a $36 \mathrm{~cm}$ capillary array and POP-4 polymer (Applied Biosystems).

\section{Calculation of Paternity Indices}

Paternity indices (PIs) were calculated using DNAVIEW 28,103 and inhouse frequency databases for Danes. STR allele frequencies will be published elsewhere. SNP allele frequencies were previously published [1, 13]. Calculations were performed under the assumption that silent alleles exist. The frequency of silent alleles was set to $(x+1) /(n+1)$, where $x$ was the number of observed silent alleles and $n$ was the total number of observed alleles. Six of the 49 SNPs are positioned on the same chromosome arm as another SNP in the multiplex [1,11], and these SNP pairs will occasionally be inherited as haplotypes and not as independent loci. Only 43 SNPs, positioned at each end of the chromosomes, were used for calculation of PI. The mutation rate of STRs and SNPs were set to 0.003 0.004 and 0.000001 , respectively.

\section{Results}

\section{Mixture Determination}

Lack of efficiency in identification of mixtures or contaminated samples has been mentioned as an important disadvantage of bi-allelic markers in forensic genetic investigations [20-22]. A sample typed with one of the standard STR kits with 10-17 STRs may easily be identified as a mixture, if more than two alleles are detected in several loci. This simple form of interpretation cannot be used for bi-allelic markers such as SNPs or insertion/deletion (indel) polymorphisms. Instead, it is necessary to analyze the relative signal strength(s) of the alleles in detail.

We developed a quality gauge on each phenotype call when the SNPforID assay was validated for relationship testing [11]. The quality gauge was based on the peak height(s) of the detected allele(s); e.g., for the locus rs1024116, the peak height ratio for heterozygous allele calls should be 1.1-2.8 (G/A), and the signal-to-noise ratio should be at least 10 and 5 for the $\mathrm{G}$ and A homozygous allele call, respectively. The pur- pose of the quality gauge was two-fold; firstly, to ensure a clear and quantitative distinction between heterozygous and homozygous allele calls, and secondly, to identify unusual phenotype calls by a simple and fast method that allows the person doing the analysis to focus on these individual results. An added bonus to the detailed analysis of every phenotype call was the important information about the sample that may be deduced by looking at the number of loci failing to fulfill the quality gauge. Many homozygous allele calls with low signal-to-noise ratios indicates that the sample was weakly amplified, which increase the risk of allele dropouts, whereas many heterozygous allele calls with unusual peak height ratios are clear indications of a mixture.

50 crime case samples were typed with the SNPforID assay. 30 samples were single-source samples, and 20 samples were judged to be two-person mixtures based on previous STR analyses. All heterozygous allele calls from the 50 samples were collected, and the peak height ratios for each locus were normalized to one by dividing by the average peak height ratio of that locus [11]. As shown in figure 2, the normalized peak height ratios from the single-source samples were approximately one, as expected. In contrast, there was a large variation in the normalized peak height ratios from two-person mixtures (fig. 2b). Almost half of the peak height ratios did not fulfill the quality gauges, and for 163 of the 631 heterozygous allele calls the peak height ratios were two times higher or lower than the acceptable range. With single-source samples, we have never observed more than one locus where the peak height ratio was two times higher or lower than the acceptable range, and in each case the ratio could be explained by a mutation in one of the primer binding sites (table 1) $[11,13]$.

It is sometimes possible to deduce the STR types of the contributors in simple mixtures. The resolution of mixed STR profiles has been described in detail previously [23, 24]. It involves an estimation of the number of individuals in the mixture, an estimation of the mixture proportion, and an analysis of all possible genotype combinations based on the signal strengths of the detected alleles. This type of analysis is not 
possible for mixed SNP (or indel) profiles. The mixture proportion or the number of contributors cannot be estimated from the SNP results alone. Even if that type of information was available from e.g. STR analyses, only the genotype of the major contributor may be deduced. Consider a 1:10 twoperson mixture where both alleles are detected. If the peak height ratio is acceptable according to the quality gauge, it is likely that the major contributor is heterozygous at that locus. However, it is impossible to deduce the phenotype of the minor contributor. The minor contributor may be heterozygous or homozygous for either allele. If the peak height ratio in a 1:10 mixture is unacceptable, the major contributor is likely to be homozygous for the allele with the strongest signal. The minor contributor is likely to carry the allele with the weakest signal, but it is not possible to deduce whether the minor contributor is homozygous or heterozygous at that locus. If the two individuals contributed more or less equally to the mixture, neither of the profiles can be deduced. Consider a locus, where the detected peak height ratio is 3 and the expected ratio is 1 . They may be achieved in two ways: i) a 3:1 mixture of two individuals that are homozygous for the two different alleles, or ii) a 2:1 mixture of a homozygous and heterozygous individual. If one of the contributors in the mixtures is known and the mixture proportion can be estimated accurately, it may be possible to deduce the bi-allelic genotypes. However, that will introduce bias into the analysis and therefore is not recommendable [24].

For complex mixtures with three or more individuals, the mixed SNP profile will be essentially useless. Both alleles are likely to be detected at a large number of loci, and any individual in the population will match the sample at these loci. Furthermore, deducing the individual SNP types, even for the major contributor, will be extremely difficult.

\section{Silent and Partially Silent Alleles}

Unusual peak height ratios were observed for some SNP loci during the validation of the SNPforID multiplex [11, 13] and during routine case work investigations. If the ratios were reproducible, and sometimes inheritable, the samples were selected for sequencing in order to determine the reasons for the unusual ratios. New PCR primer sets for five loci were designed (table 1), and the PCRs were optimized. The resulting fragments included the entire fragment amplified with the SNPforID multiplex and allowed sequencing of both the PCR and SBE primer sequences used in the SNPforID assay. Four SNPs in primer binding sites and one apparent deletion were identified in the 5 loci (table 1). Three of the SNPs were recently characterized by the 1,000 Genomes Project ( $w w w$. genome.gov), whereas the SNP near the rs763869 locus was unknown. The deletion in the rs1031825 locus was detected in two related individuals (father and child). The individuals were apparently homozygous for the deletion since no signals from the SBE reaction and no amplification products were detected in either individual. The SNPs near the rs1029047
Table 2. Likelihood ratios

\begin{tabular}{llll}
\hline & 18 STRs & 43 SNPs & Combined \\
\hline PI (AF1) & $5.4 \times 10^{8}$ & $1.3 \times 10^{8}$ & $7.0 \times 10^{16}$ \\
PI (AF2) & $1.9 \times 10^{5}$ & $4.6 \times 10^{-2}$ & $8.9 \times 10^{3}$ \\
LR $=\mathrm{P}\left(\mathrm{E} \mid \mathrm{H}_{1}\right) / \mathrm{P}\left(\mathrm{E} \mid \mathrm{H}_{2}\right)^{\dagger}$ & $2.9 \times 10^{3}$ & $2.8 \times 10^{9}$ & $7.8 \times 10^{12}$ \\
\hline
\end{tabular}

${ }^{\dagger} \mathrm{H}_{1}$ : AF1 is the father. $\mathrm{H}_{2}$ : AF2 is the father.

and the rs938283 loci were observed in 10 and 5 unrelated individuals of African descent, respectively. The other polymorphisms were only observed in one or two families.

\section{Case Example}

A complicated relationship case with four closely related individuals was investigated. There was strong suspicion of incest between the mother $(\mathrm{M})$ of an unborn boy $(\mathrm{C})$ and either her father (AF1) or her full sibling (AF2). The question raised was, whether the father or the brother of the mother was the father of the child (fig. 1). After the initial investigation of 18 autosomal STRs, neither AF1 nor AF2, could be excluded as the father, and both men were included according to the Danish rules of reporting a $\mathrm{PI}>10^{4}$ (table 2). One genetic inconsistency between the child and AF2 or between the child and the mother was observed in D13S317 (fig. 1c). If a mutation had occurred, it would have been a 4-step mutation, which is a rare mutation event $[25,26]$. Nevertheless, the results in D13S317 accounts for almost all of the difference in PI between AF1 and AF2, and it was not possible to deduce whether AF1 or AF2 was the father. Supplementary investigations of 49 SNPs using the SNPforID multiplex were performed, and two additional mismatches were observed (fig. 1c). At the rs1029047 locus, there was a genetic inconsistency between the child and AF2 or between the child and the mother, and at the rs733164 locus, C and AF2 were homozygous for different alleles. The SNP results clearly indicated that AF2 was not the father, and the PI for AF2 was less than 1. Based on the combined STR and SNP results, it was reported that AF1 was more than 1 million times as likely to be the father as AF2.

AF1 was presumed to be the father of M and AF2 (PI was $4 \times 10^{14}$ and $6 \times 10^{16}$, respectively) in all calculations; however, there was a mismatch between AF1 and both M and AF2 at the rs1029047 locus (fig. 1c). Sequencing confirmed that AF1 was homozygous A at the rs1029047 locus, but heterozygous $\mathrm{A} / \mathrm{T}$ at a position $9 \mathrm{bp}$ upstream of rs1029047 (data not shown). This SNP (rs79672047) was reported to the NCBI dbSNP database in March 2011 by the 1,000 Genomes Project, and it was identified by sequencing in 10 unrelated individuals and 5 of their family members (table 1). Presumably, the rs79672047 T allele resulted in weak binding of the rs1029047 SBE primer to the PCR products. A very faint A signal was sometimes detected with the SNPforID multiplex in some individuals, but often the signal was lost completely. Sequencing 
revealed that $\mathrm{M}$ and $\mathrm{AF} 2$ were heterozygous at both the rs1029047 and the rs79672047 locus, and, apparently, AF1 passed on the rs79672047 T / rs1029047 A haplotype, which results in a silent rs1029047 A allele with the SNPforID multiplex assay, to M and AF2, whereas AF1 passed on the normal rs79672047 A / rs1029047 A haplotype to the child C.

\section{Discussion}

The SNPforID multiplex assay was validated for relationship case work in our laboratory in 2007, where it replaced typing of variable number of tandem repeats (VNTRs) [11, 13]. Today, the assay is used in all cases that are not trios (womanchild-man) and in all cases where 1-2 mismatches were detected between the child and one of the alleged parents. Approximately 80 cases with SNP typing results are reported each year. Half are paternity cases, and the other half are immigration cases. The case example shown above is a good example of how useful the SNPforID assay is in complicated relationship cases, and we recently published other case examples from our own laboratory [27, 28] and case examples from other laboratories that were reinvestigated with the SNPforID assay [29]. The assay itself has worked robustly after the improvements made during the validation [11], and the typing success rate for any SNP in any experiment since the assay was introduced in routine case work was $98 \%$. Full SNP profiles were obtained in $78 \%$ of all experiments, which is 10 $15 \%$ lower than the number of full STR profiles obtained with the AmpFlSTR Identifiler (unpublished data) and the AmpFlSTR Identifiler direct kits [30]. With a few exceptions (table 1), full SNP profiles from duplicate typings were reported for all individuals.

The introduction of the quality gauge on each phenotype call [11] greatly simplified the analyses of the electropherograms and standardized the process. Analysis is no longer an expert evaluation of the typing results. Instead, it can be documented how analysis should proceed and what guidelines apply to each phenotype call. Interlaboratory exercises within the SNPforID consortium [2] and the European DNA Profiling Group [31] revealed that most errors occurred in the analysis of the electropherograms. Clearly, it was inconvenient for the analyst that the alleles from the same locus appeared in separate windows and that the signal strengths of the two alleles were not balanced, which increased the risk of false in- terpretation of the results. The quality gauges overcome most of these problems. Unfortunately, there is no analysis software available, where the quality gauges may be defined. Instead, a text file must be exported from the analysis software, and the typing results must be analyzed in a simple spreadsheet. This is inconvenient and somewhat time-consuming. If the quality gauges could be defined in the analysis software, analysis would be simple and swift.

Identification of mixtures or contaminated samples is essential to all forensic genetic investigations. Clearly, it is easier to identify mixtures with highly polymorphic markers, such as STRs, than with bi-allelic markers. However, the results in figure 2 demonstrate that mixtures can be identified easily also with SNP markers. Two unrelated individuals from the Danish allele frequency database with 371 individuals have an average of 20-21 identical phenotypes (range 6-37). Thus, it is expected that mixed SNP profiles cannot fulfill the predefined quality gauges in many loci, which is confirmed by the results in figure 2. The experiment in figure 2 is used as a training set for new analysts in our laboratory. So far, the trained analysts have been able to identify all mixtures. Furthermore, we have been able to identify all mixtures in controlled two-person mixture experiments with mixture ratios from $1: 1$ up to $1: 40$ if there were at least $50-100 \mathrm{pg}$ of the minor contributor in the mixture (data not shown) [11].

Today, the SNPforID multiplex is a routine investigation in our laboratory. It provides us with an assay that can solve most relationship cases with high statistical weight and with a very low risk of detecting a mutation. Furthermore, it makes it possible to type highly degraded sample materials. In combination, the SNPforID multiplex provides us with an assay that is very well suited for disaster victim identifications, where the samples from the victims may be highly degraded and the victims need to be identified via their relatives.

\section{Acknowledgements}

We thank Nadia Jochumsen, Trine Hansen, Maibritt Sigvardt and Anja Jørgensen for technical assistance.

\section{Disclosure Statement}

The authors did not provide a conflict of interest statement.

\section{References}

1 Sanchez JJ, Phillips C, Børsting C, Balogh K, Bogus M, Fondevilla M, Harrison CD, MusgraveBrown E, Salas A, Syndercombe-Court D, Schneider PM, Carracedo A, Morling N: A multiplex assay with 52 single nucleotide polymorphisms for human identification. Electrophoresis 2006;27: $1713-1724$.
Musgrave-Brown E, Ballard D, Balogh K, Bender K, Berger B, Bogus M, Børsting C, Brion M, Fondevila M, Harrison C, Oguzturun C, Parson W, Phillips C, Proff C, Ramos-Luis E, Sanchez JJ, Diz PS, Rey B, Stradmann-Bellinghausen B, Thacker C, Carracedo A, Morling N, Scheithauer R, Schneider PM, Court DS: Forensic validation of the SNPforID 52-plex assay. Forensic Sci Int Genet 2007;1:186-190.
3 Phillips C, Fondevila M, García-Magarinos M, Rodriguez A, Salas A, Carrecedo A, Lareu MV: Resolving relationship tests that show ambiguous STR results using autosomal SNPs as supplementary markers. Forensic Sci Int Genet 2008;2:198-204. 
4 Lou C, Cong B, Li S, Fu L, Zhang X, Feng T, Su S, Ma C, Yu F, Ye J, Pei L: A SNaPshot assay for genotyping 44 individual identification single nucleotides polymorphisms. Electrophoresis 2011;32: 368-378.

5 Tomas C, Axler-DiPerte G, Budimlija ZM, Børsting C, Coble MD, Decker AE, Eisenberg A, Fang $\mathrm{R}$, Fondevila M, Fredslund SF, Gonzalez S, Hansen AJ, Hoff-Olsen P, Haas C, Kohler P, Kriegel AK, Lindblom B, Manohar F, Maroñas O, Mogensen HS, Neureuther K, Nilsson H, Scheible MK, Schneider PM, Sonntag ML, Stangegaard M, Syndercombe-Court D, Thacker CR, Vallone PM, Westen AA, Morling N: Autosomal SNP typing of forensic samples with the GenPlex ${ }^{\mathrm{TM}}$ HID System: Results of a collaborative study. Forensic Sci Int Genet 2011;5:369-375.

6 Wenk RE, Gjertson DW, Chiafari FA, Houtz T: The specific power of parentage exclusion in a child's blood relatives. Transfusion 2005;45:440-444.

7 Poetsch M, Lüdcke C, Repenning A, Fisher L, Mályusz V, Simeoni E, Lignitz E, Oehmichen M, von Wurmb-Schwark N: The problem of single parent/ child paternity analysis - practical results involving 336 children and 348 unrelated men. Forensic Sci Int 2006;159:98-103.

8 Von Wurmb-Schwark N, Mályusz V, Simeoni E, Lignitz E, Poetsch M: Possible pitfalls in motherless paternity analysis with related putative fathers. Forensic Sci Int 2006;159:92-97.

9 Karlsson AO, Holmlund G, Egeland T, Mostad P DNA-testing for immigration cases: the risk of erroneous conclusions. Forensic Sci Int 2007;172:144149.

10 Nothnagel M, Schmidtke J, Krawczak M: Potentials and limits of pairwise kinship analysis using autosomal short tandem repeat loci. Int J Legal Med 2010;124:205-215.

11 B $\emptyset$ rsting C, Rockenbauer E, Morling N: Validation of a single nucleotide polymorphism (SNP) typing assay with 49 SNPs for forensic genetic testing in a laboratory accredited according to the ISO 17025 standard. Forensic Sci Int Genet 2009;4:34-42.

-12 Rockenbauer E, Børsting C, Stangegaard M, Frank-Hansen R, Morling N: Successful STR and SNP typing of FTA-card samples with low amounts of DNA after DNA extraction using a Qiagen BioRobot ${ }^{\circledR}$ EZ1. Forensic Sci Int Genet Suppl 2009; 2:83-84.
13 Børsting C, Sanchez JJ, Hansen HE, Hansen AJ, Bruun HQ, Morling N: Performance of the SNPforID 52 SNP-plex assay in paternity testing. Forensic Sci Int Genet 2008;2:292-300.

14 Porras L, Phillips C, Fondevilla M, Beltran L, Ortiz T, Rondon F, Barreto G, Larau MV, Henao J, Carrecedo A: Genetic variability of the SNPforID 52-plex identification SNP panel in Central West Columbia. Forensic Sci Int Genet 2009;4:e9-e10

15 Drobnic K, Børsting C, Rockenbauer E, Tomas C, Morling N: Typing of 49 autosomal SNPs by SNaPshot ${ }^{\circledR}$ in the Slovenian population. Forensic Sci Int Genet 2010;4:e125-e127.

16 Santos C, Phillips C, Fondevilla M, Porras-Hurtado L, Carrecedo A, Souto L, Lareu MV: A study of East Timor variability using the SNPforID 52-plex SNP panel. Forensic Sci Int Genet 2011;5:e25-e26.

17 Poulsen L, Børsting C, Tomas C: Typing of Amerindian Kichwas and Mestizos from Ecuador with the SNPforID multiplex. Forensic Sci Int Genet 2011;5:e105-e107.

18 Amigo J, Phillips C, Lareu MV, Carrecedo A: The SNPforID browser: an online tool for query and display of frequency data from the SNPforID project. Int J Legal Med 2008;122:435-440.

19 Børsting C, Sanchez JJ, Morling N: Forensic genetic DNA typing with PCR-based methods; in Hughes S, Moody A (eds): PCR. Method Express Series. Bloxham, Scion Publishing, 2007, pp 123-142.

20 Gill P, Werrett DJ, Budowle B, Guerrieri R: An assessment of whether SNPs will replace STRs in national DNA databases - joint considerations of the DNA working group of the European Network of Forensic Science Institutes (ENFSI) and the Scientific Working Group on DNA Analysis Methods (SWGDAM). Sci Justice 2004:44:51-53.

21 Butler JM, Coble MD, Vallone PM: STRs vs. SNPs: thoughts on the future of forensic DNA testing. Forensic Sci Med Pathol 2007;3:200-205.

22 Budowle B, van Daal A: Forensically relevant SNP classes. Biotechniques 2008;44:603-610.

23 Clayton TM, Whitaker JP, Sparkes R, Gill P: Analysis and interpretation of mixed forensic stains using DNA STR profiling. Forensic Sci Int 1998;91: $55-70$.
24 Gill P, Brenner CH, Buckleton JS, Carrecedo A, Krawczak M, Mayr WR, Morling N, Prinz M, Schneider PM, Weir BS: DNA commission of the International Society of Forensic Genetics: recommendations on the interpretation of mixtures. Forensic Sci Int 2006;160:90-101.

25 Goedbloed M, Vermeulen M, Fang RN, Lembring M, Wollstein A, Ballantyne K, Lao O, Brauer S, Krüger C, Roewer L, Lessig R, Ploski R, Dobosz T, Henke L, Henke J, Furtado MR, Kayser M: Comprehensive mutation analysis of 17 Y-chromosomal short tandem repeat polymorphisms included in the AmpFISTR Yfiler PCR amplification kit. Int J Legal Med 2009;123:471-482.

26 Ballantyne KN, Goedbloed M, Fang R, Schaap O, Lao O, Wollstein A, Choi Y, van Duijn K, Vermeulen M, Brauer S, Decorte R, Poetsch M, von Wurmb-Schwark N, de Knijff P, Labuda D, Vézina H, Knoblauch H, Lessig R, Roewer L, Ploski R, Dobosz T, Henke L, Henke J, Furtado MR, Kayser M: Mutability of Y-chromosomal microsatellites: rates, characteristics, molecular bases, and forensic implications. Am J Hum Genet 2010;87:341-353.

27 Tomas C, Sanchez JJ, Castro JA, Børsting C, Morling N: Forensic usefulness of a $25 \mathrm{X}$-chromosome SNP marker set. Transfusion 2010;50:2258-2265.

28 B $\varnothing$ rsting C, Morling N: Mutations and/or relatives? Six case work examples where 49 autosomal SNPs were used as supplementary markers. Forensic Sci Int Genet 2011;5:236-241.

29 Børsting C, Morling N: Re-investigations of six unusual paternity cases by typing of autosomal single nucleotide polymorphisms. Transfusion 2012;52: 425-430.

30 Stene M, Buchard A, B $\varnothing$ rsting C, Morling N: Validation of the AmpFlSTR ${ }^{\circledR}$ Identifiler $^{\circledR}$ Direct PCR amplification kit in a laboratory accreditated according to the ISO17025 standard. Forensic Sci Int Genet Suppl 2011;3:e165-e166.

31 Sanchez JJ, Børsting C, Balogh K, Berger B, Bogus M, Butler JM, Carrecedo A, Court DS, Dixon LA Eichmann C, Fondevila M, Gill P, Harrison CD, Hohoff C, Huel R, Ludes B, Parson W, Parsons TJ, Petkovski E, Phillips C, Schmitter H, Schneider PM, Vallone PM Morling N: Forensic typing of autosomal SNPs with a 29 SNP-multiplex - results of a collaborative EDNAP exercise. Forensic Sci Int Genet 2008;2:176-183. 